\title{
Thermal decomposition properties and compatibility of CL-20 with binders HTPB, PBAN, GAP and polyNIMMO
}

\author{
T. Gołofit • K. Zyśk
}

Received: 31 August 2014/ Accepted: 9 January 2015/Published online: 31 January 2015

(C) The Author(s) 2015. This article is published with open access at Springerlink.com

\begin{abstract}
The compatibility of filler 2,4,6,8,10,12-hexanitro-2,4,6,8,10,12-hexaazaisowurtzitane (CL-20) with rocket propellant binders: hydroxyl-terminated polybutadiene (HTPB), butadiene-acrylonitrile-acrylic acid terpolymer (PBAN), glycidyl azide polymer (GAP) and poly(3-nitratomethyl-3-methyloxetane) (polyNIMMO), has been examined. The compatibility of the compounds has been tested in accordance with the STANAG 4147 standard and its modification consisting in the change of the heating rate. As it arises from STANAG 4147 standard criterion, CL-20 is not compatible with polyNIMMO, PBAN and GAP and possibly incompatible with HTPB. Changes of relative position of peaks between measurements performed in hermetical pans and pans with a pinhole and with different heating rate were observed. In case of polyNIMMO and HTPB, changes of measurement parameters lead to estimated compatibility change. The analysis of the thermal decomposition of CL-20 revealed that it is a two-phase process. The first phase is associated with decomposition in solid phase; the second phase is associated with decomposition of volatile intermediate products of CL-20 decomposition. Due to the complex process of decomposition of tested samples, the apparent activation energy was used for the assessment of the compatibility. The apparent activation energy of the initial phase of decomposition CL-20 and its mixtures with binders are compatible with one another within the limits of measurement error. Results of measurement of apparent activation energy do not indicate a destabilizing effect of binders on the initial phase of decomposition of CL-20.
\end{abstract}

T. Gołofit $(\bowtie) \cdot$ K. Zyśk

Faculty of Chemistry, Warsaw University of Technology,

Noakowskiego 3, 00-664 Warsaw, Poland

e-mail: tomgol@ch.pw.edu.pl
Keywords CL-20 - Binder - Compatibility - DSC . Thermal decomposition kinetics · STANAG 4147

\section{Introduction}

Binders such as hydroxyl-terminated polybutadiene (HTPB), butadiene-acrylonitrile-acrylic acid terpolymer (PBAN), glycidyl azide polymer (GAP) and poly(3-nitratomethyl-3-methyloxetane) (polyNIMMO) are substances added to rocket propellants in purpose to bond solid components of propellant and to give it the appropriate mechanical properties. Fast burning rocket propellants, with a high specific impulse, very commonly contain ammonium chlorate(VII) (AP) and aluminium (Al) in addition to binders in its composition [1]. The main disadvantage of such propellants is the formation of signature during engine operation, which allows easy detection of a flying rocket and its launch site. The signature can be reduced by the elimination of $\mathrm{Al}$ and reduction of AP. These components can be replaced with a high-energy filler such as 2,4,6,8,10,12hexanitro-2,4,6,8,10,12-hexaazaisowurtzitane (CL-20). In order to ensure the safe storage and use of rockets, propellant components should be compatible with each other [2-8]. The NATO Standardization Agency recommends determination of compatibility at heating rate of $2 \mathrm{~K} \mathrm{~min}^{-1}$ [7]. There are some descriptions found in the literature which concern the compatibility examinations performed at heating rate of $10 \mathrm{~K} \mathrm{~min}^{-1}[2,8]$. However, the best influence visibility of one substance on thermal decomposition of the other can be obtained by analysing changes of kinetic parameters of decomposition reaction $[3,5,6]$. In accordance with the recommendations of International Confederation for Thermal Analysis and Calorimetry (ICTAC), full kinetic analysis should be based on the determination of the activation 
energy, pre-exponential factor and reaction model [9]. During the decomposition of high-energy materials, and especially a multicomponent mixture, many parallel and successive reactions can proceed [5,9]. Determined kinetic parameters are the result of all the processes taking place during the decomposition of the sample. Therefore, it is difficult to determine the model of such a decomposition reaction. Without assuming the reaction model, it is impossible to determine the pre-exponential factor. Recommended isoconversional methods allow estimating the activation energy without assuming any reaction model. For practical reasons, in this study, the effect of one compound on the thermal degradation of the second compound in the mixture was analysed by changes in the activation energy. Due to the complex process of decomposition of tested samples, determined parameter in the later work is called the apparent activation energy ${ }_{\mathrm{a}} \mathrm{Ea}$. Uncontrolled decomposition of a high-energy mixture, caused for example by the lack of compatibility, may lead to the thermal explosion [10]. Such an event can occur even in low degrees of conversion [11]. For this reason, the influence of ingredients on the changes in the apparent activation energy was analysed for the initial level of conversion.

The following paper presents the study of the compatibility of CL-20 with selected binders of heterogeneous rocket propellants. The compatibility was determined in hermetic pans and in pans with a pinhole at two different heating rates: 2 and $10 \mathrm{~K} \mathrm{~min}^{-1}$. The influence of the measurement conditions on the determined compatibility was analysed. The apparent activation energy of decomposition reaction of the examined mixtures and their components was determined and compared depending on the degree of conversion. The results of compatibility of the studied systems determined by comparison of peaks were compared with the results of compatibility determined by comparison of the activation energy changes.

\section{Experimental}

Materials

\&CL-20 (impact sensitivity about $4 \mathrm{~J}$ ) with the chemical purity of $98 \%$ and the polymorphic purity $>95 \%$ was synthesized in the Department of High Energetic Materials of the Faculty of Chemistry at the Technological University of Warsaw, Poland. GAP and polyNIMMO with the chemical purity of $98 \%$ were synthesized in the Industrial Chemistry Research Institute, Poland. HTPB was synthesized at the Industrial Chemistry Research Institute, Poland, $\mathrm{Mn}=2,500, \mathrm{Mw}=4,000, \mathrm{OH}=1.2 \mathrm{meq}^{-1}$, water content max. $0.2 \%$. PBAN is manufactured by the Research and Development Centre of Rubber and Vinyl
Plastics (OBR KiTW) in Oświęcim, Mn 2230. Binary mixtures used in the study were obtained by grinding components in an agate mortar at the mass ratio of 1:1.

\section{Experimental techniques}

The measurements were carried out using the Differential Scanning Calorimeters Pyris1 made by PerkinElmer and the Q2000 made by TA Instruments. Measuring conditions were as follows:

- heating rate of $\beta=0.5,1,2,5,7,10$ and $15 \mathrm{~K} \mathrm{~min}^{-1}$,

- measurements were carried out in hermetic pans, sample mass $0.5 \pm 0.1 \mathrm{mg}$,

- measurements were carried out in hermetic pans with a 0.7 -mm pinhole, sample mass $1.0 \pm 0.1 \mathrm{mg}$, single components, mixture $2.0 \pm 0.1 \mathrm{mg}$.

\section{Compatibility}

The compatibility was determined according to the method specified in STANAG 4147 [7]. The measurements were carried out for samples of the tested substances with a mass of $1 \pm 0.1 \mathrm{mg}$ and $1: 1(\mathrm{w} / \mathrm{w})$ mixture with a mass of $2 \pm 0.1 \mathrm{mg}$ in pans with a pinhole, at a heating rate of $\beta=2 \mathrm{~K} \mathrm{~min}^{-1}$. Decomposition peak minimum temperatures of CL-20 $\left(T_{a}\right)$ were compared with values obtained for the mixture of CL-20 with other ingredient $\left(T_{a b}\right)$. If $T_{a b}$ of mixture decomposition is more than $20 \mathrm{~K}$ lower in relation to $T_{a}$ (CL-20), then CL-20 is incompatible with this other ingredient. If the shift in the direction of lower temperatures is in the range of $4-20 \mathrm{~K}$, then CL-20 is uncertainly compatible with the other ingredient and it demands further investigation. CL-20 is compatible with the analysed ingredient when $T_{a b}$ is maximum $4 \mathrm{~K}$ lower than CL-20 decomposition temperature $T_{a}$.

Kinetic parameter calculation methods

Kinetic parameters of the decomposition of the studied systems were determined by using the program Thermokinetics 3.1 NETZSCH. The measurements were carried out at different the heating rate $(\beta=0.5,1,2,5,7,10$ and $15 \mathrm{~K} \mathrm{~min}^{-1}$ ) in hermetic pans. In accordance with the recommendations of ICTAC, the apparent activation energy a Ea was determined by Friedman's isoconversional method [9, 12].

\section{Results and discussion}

The analysis of thermal decomposition of HTPB, PBAN, GAP, polyNIMMO, CL-20 samples and binder mixtures of 
CL-20 was conducted. The measurements were carried out in accordance with STANAG 4147 [7]. Modification consisting in the heating rate change (from $\beta=2$ to $\beta=10 \mathrm{~K} \mathrm{~min}^{-1}$ ) was also applied. It was used by some authors in the past [2, 8]. Exemplary studies of CL-20 with polyNIMMO, with the use of methods discussed above, are presented in Figs. 1-4.

Figure 1 shows the DSC curves of the thermal decomposition of samples obtained during the measurements performed at the heating rate of $\beta=2 \mathrm{~K} \mathrm{~min}^{-1}$ in pans with a pinhole. These conditions are in accordance with STANAG 4147 [7]. The temperature of CL-20 decomposition peak minimum equals $500 \mathrm{~K}$, while this value for the 1:1 (w/w) polyNIMMO/CL-20 mixture $T_{\mathrm{ab}}=474 \mathrm{~K}$. The temperature of mixture decomposition peak minimum $T_{\mathrm{ab}}$ is then $26 \mathrm{~K}$ lower than $T_{\mathrm{a}}$ temperature which testifies to the incompatibility of CL-20 to polyNIMMO according to STANAG 4147 standard.

Figure 2 shows the measurements performed in hermetic pans at a heating rate of $\beta=2 \mathrm{~K} \mathrm{~min}^{-1}$. The temperature of CL-20 decomposition peak minimum equals $499 \mathrm{~K}$, while this value for the $1: 1(\mathrm{w} / \mathrm{w})$ polyNIMMO/CL20 mixture $T_{\mathrm{ab}}=474 \mathrm{~K}$. The temperature of mixture decomposition peak minimum $T_{\mathrm{ab}}$ is then $25 \mathrm{~K}$ lower than $T_{\mathrm{a}}$ temperature which testifies to the incompatibility of CL20 to polyNIMMO according to STANAG 4147 standard. The use of hermetic pans caused a change in shape of decomposition peak of CL-20. The two-phase nature of the decomposition process is clearly visible. This indicates that intermediate volatile products are formed during decomposition of CL-20.

Figure 3 shows the measurements performed at the heating rate of $\beta=10 \mathrm{~K} \mathrm{~min}^{-1}$ in pans with a pinhole. This method differs from the one proposed in STANAG
4147 (Fig. 1) due to the change of heating rate from $\beta=2$ to $\beta=10 \mathrm{~K} \mathrm{~min}^{-1}$. The temperature of CL-20 decomposition peak minimum equals $505 \mathrm{~K}$, while this value for the 1:1 (w/w) polyNIMMO/CL-20 mixture $T_{\mathrm{ab}}=486 \mathrm{~K}$. The temperature of $T_{\mathrm{ab}}$ is then $19 \mathrm{~K}$ lower than $T_{\mathrm{a}}$ temperature. According to the STANAG 4147 standard, CL-20 is then uncertainly compatible with polyNIMMO. The increase of the heating rate from $\beta=2$ to $\beta=10 \mathrm{~K} \mathrm{~min}^{-1}$ caused the change of compatibility analysis result of CL-20 to polyNIMMO and the change of CL-20 decomposition peak shape. Also in this case, the two-phase nature of decomposition is visible.

Figure 4 shows the measurements performed in hermetic pans at the heating rate of $\beta=10 \mathrm{~K} \mathrm{~min}^{-1}$. This method differs from the method proposed in STANAG 4147 (Fig. 1) with the increase of the heating rate from $\beta=2$ to $\beta=10 \mathrm{~K} \mathrm{~min}^{-1}$. The temperature of $\mathrm{CL}-20$ decomposition peak minimum equals the $529 \mathrm{~K}$, while for the $1: 1(\mathrm{w} / \mathrm{w})$ polyNIMMO/CL-20 mixture $T_{\mathrm{ab}}=491 \mathrm{~K}$. The temperature of mixture decomposition peak minimum $T_{\mathrm{ab}}$ is then $38 \mathrm{~K}$ lower than CL-20 $T_{\mathrm{a}}$ temperature which testifies to the incompatibility of CL-20 to polyNIMMO, according to STANAG 4147 standard. The change of measurement parameters caused the change of the shift of mixture decomposition peak minimum in relation to CL-20 decomposition peak minimum from $T_{\mathrm{ab}}-T_{\mathrm{a}}=-38 \mathrm{~K}$ to $T_{\mathrm{ab}}-T_{\mathrm{a}}=-19 \mathrm{~K}$.

Using the four methods described above, compatibility of CL-20 with PBAN, HTPB and GAP has been determined. Table 1 summarizes the results of the compatibility tests.

According to the criterion of STANAG 4147 standard, CL-20 is incompatible with polyNIMMO, PBAN and GAP and possibly incompatible with HTPB. The changes of
Fig. 1 DSC curves of thermal decomposition of CL-20, and polyNIMMO/CL-20 mixture $1: 1(\mathrm{w} / \mathrm{w}), \beta=2 \mathrm{~K} \mathrm{~min}^{-1}$, measurement carried out in a pan with a pinhole

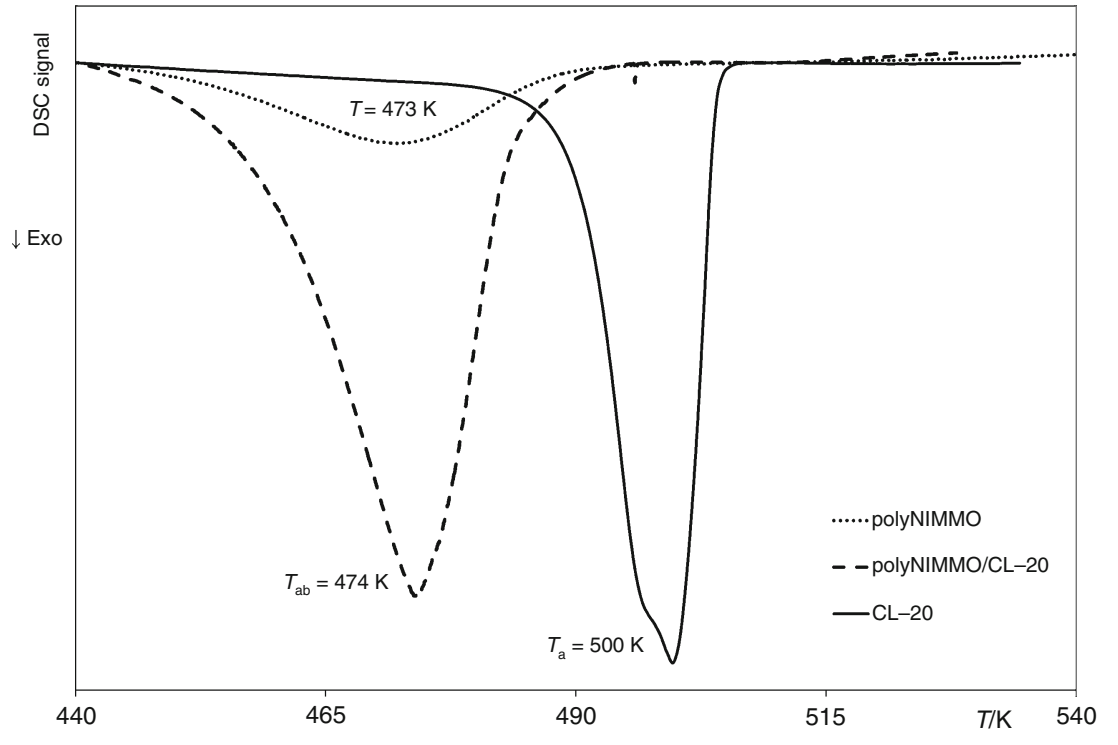


Fig. 2 DSC curves of thermal decomposition of CL-20, and 1:1 (w/w) polyNIMMO/CL-20 mixture, $\beta=2 \mathrm{~K} \mathrm{~min}^{-1}$, measurement carried out in a hermetic pan
Fig. 3 DSC curves of thermal decomposition of CL-20, and polyNIMMO/CL-20 mixture $1: 1(\mathrm{w} / \mathrm{w}), \beta=10 \mathrm{~K} \mathrm{~min}^{-1}$, measurement carried out in a pan with a pinhole
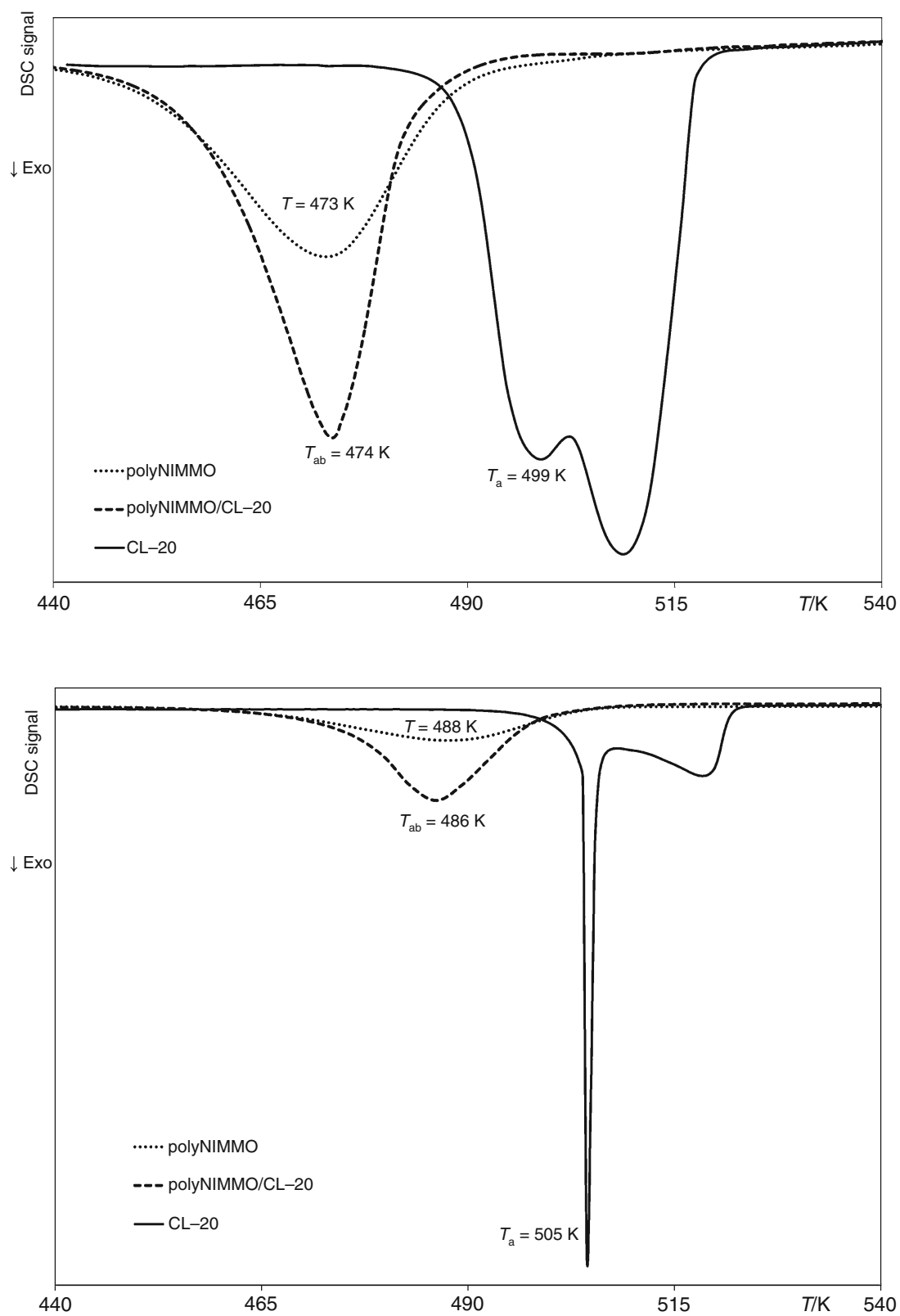

relative peaks positions were observed after pan type changing (from hermetical pan to the pan with a pinhole), but estimated compatibility did not change. The increase of heating rate from $\beta=2$ to $\beta=10 \mathrm{~K} \mathrm{~min}^{-1}$ caused the change of relative peaks positions, which lead to the change of estimated compatibility in case of polyNIMMO and HTPB.

The kinetic parameters were determined with regard to the decomposition of CL-20, polyNIMMO binders, PBAN, HTPB, GAP and their mixtures with CL-20. The series of measurements of the CL-20 decomposition carried out at different heating rates are shown in Fig. 5.

As expected, along with the increase of heating rate, the decomposition process of CL-20 moves in the direction of higher temperatures. At lower heating rates (0.5-7.0 $\mathrm{K} \mathrm{min}^{-1}$ ), two-phase nature of CL-20 decomposition is clearly visible. The two-phase CL-20 decomposition process has already been described in the literature [5, 13]. Figure 6 shows the influence of pan types on the nature of the CL-20 decomposition process for heating rate of 2.0 and $10.0 \mathrm{~K} \mathrm{~min}^{-1}$.

In the measurements performed at a heating rate of $2.0 \mathrm{~K} \mathrm{~min}^{-1}$, the first stage of decomposition observed in hermetic pans is consistent with the total decomposition observed in a pan with a pinhole. For this heating rate, the two-phase process is more clear, when measured in a hermetic pan. In the measurements performed at the heating rate of $10.0 \mathrm{~K} \mathrm{~min}^{-1}$, the second stage of decomposition 
Fig. 4 DSC curves of thermal decomposition of CL-20, polyNIMMO and polyNIMMO/ CL-20 mixture 1:1 (w/w), $\beta=10 \mathrm{~K} \mathrm{~min}^{-1}$, measurement carried out in a hermetic pan

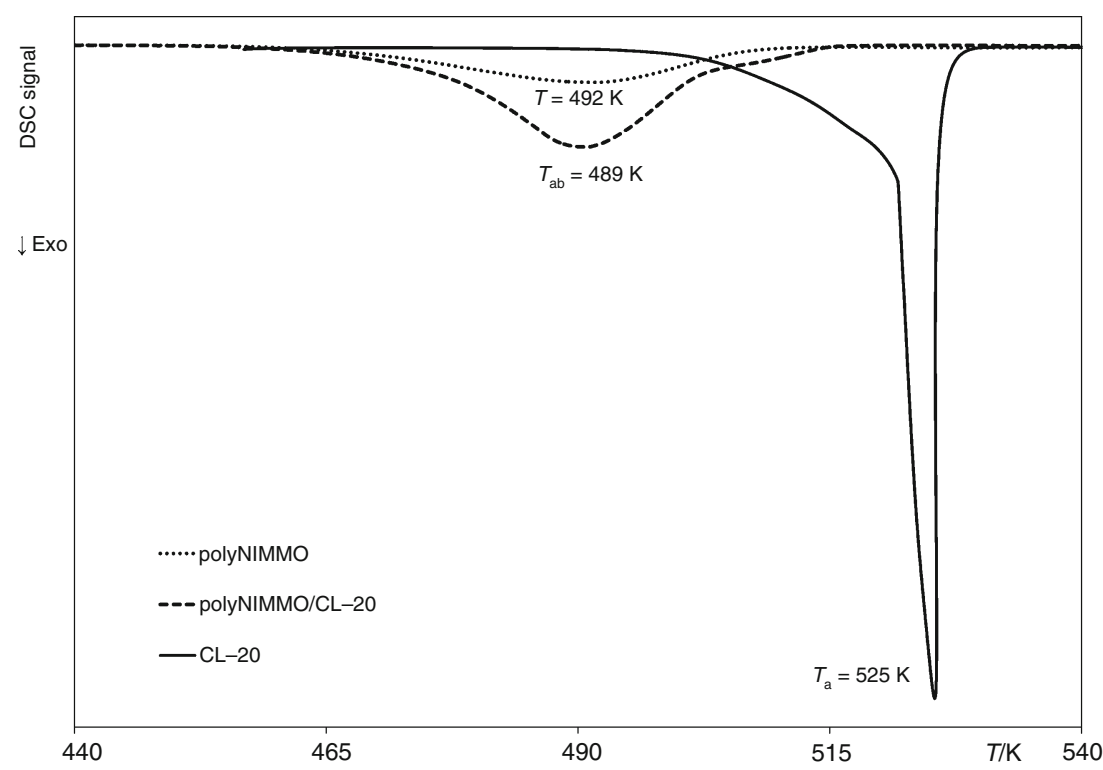

Table 1 Results of compatibility tests $\left(C_{\mathrm{ab}}\right)$ of CL-20 with polyNIMMO, PBAN, HTPB, GAP, determined in the performed measurements in pans with a pinhole and hermetic pans, at a heating rate of $\beta=2$ and $10 / \mathrm{K} \mathrm{min}^{-1}$

\begin{tabular}{|c|c|c|c|c|c|c|c|c|}
\hline \multirow[t]{3}{*}{ CL-20 with } & \multicolumn{4}{|c|}{$\beta=2 / \mathrm{K} \mathrm{min}^{-1}$} & \multicolumn{4}{|c|}{$\beta=10 / \mathrm{K} \mathrm{min}^{-1}$} \\
\hline & \multicolumn{2}{|c|}{ Pans with a pinhole } & \multicolumn{2}{|c|}{ Hermetic pans } & \multicolumn{2}{|c|}{ Pans with a pinhole } & \multicolumn{2}{|c|}{ Hermetic pans } \\
\hline & $T_{\mathrm{ab}}-T_{\mathrm{a}} / \mathrm{K}$ & $C_{\mathrm{ab}}$ & $T_{\mathrm{ab}}-T_{\mathrm{a}} / \mathrm{K}$ & $C_{\mathrm{ab}}$ & $T_{\mathrm{ab}}-T_{\mathrm{a}} / \mathrm{K}$ & $C_{\mathrm{ab}}$ & $T_{\mathrm{ab}}-T_{\mathrm{a}} / \mathrm{K}$ & $C_{\mathrm{ab}}$ \\
\hline polyNIMMO & -26 & - & -25 & - & -19 & \pm & -38 & - \\
\hline PBAN & -30 & - & -27 & - & -29 & - & -33 & - \\
\hline НТРВ & -20 & \pm & -18 & \pm & -31 & - & -27 & - \\
\hline GAP & -31 & - & -48 & - & -31 & - & -36 & - \\
\hline
\end{tabular}

$T_{\mathrm{a}}$-minimum peak decomposition temperature of less stable substances, $T_{\mathrm{ab}}$-minimum peak decomposition temperature of mixture, "+" compatible, “土”-possible incompatibility, "-"—not compatible

Fig. 5 DSC curves of the thermal decomposition of CL20 carried out at different heating rates

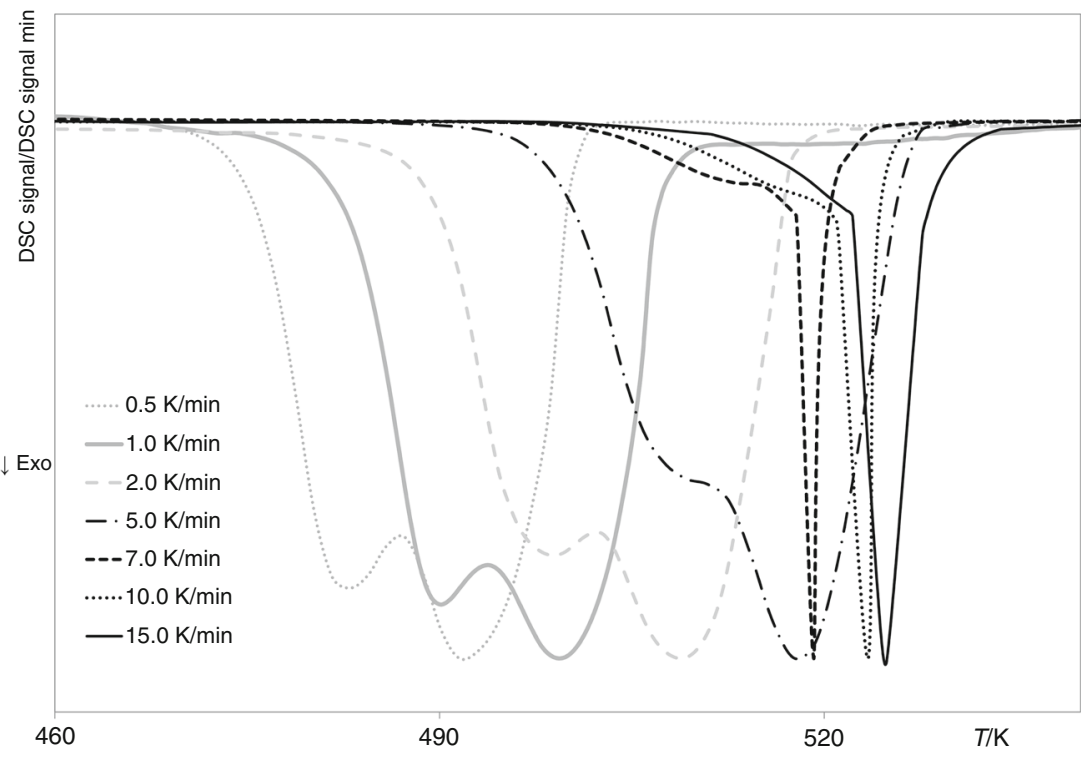


Fig. 6 DSC curves of the thermal decomposition of CL20 carried out in hermetic pans with a pinhole, with heating rates of 2.0 and $10.0 \mathrm{~K} \mathrm{~min}^{-1}$

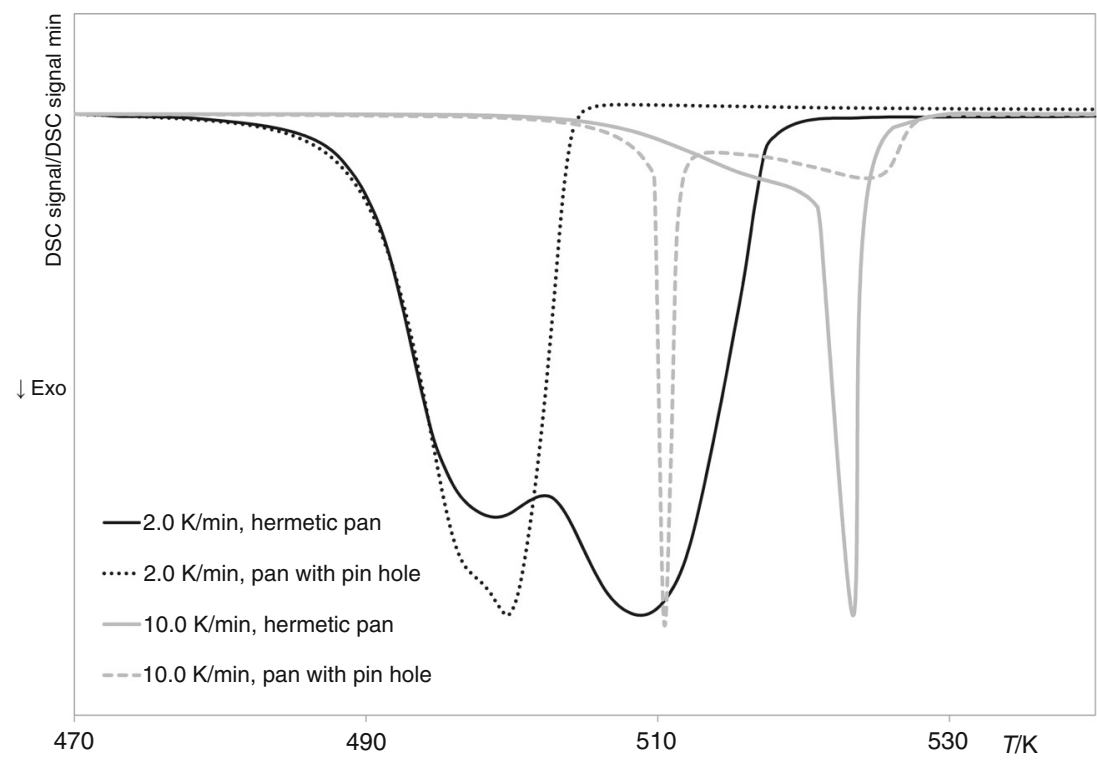

observed in a pan with a pinhole is consistent with the total decomposition observed in a hermetic pan. For this heating rate, the two-phase process is more clear, when measured in a pan with a pinhole. The observed compliance indicates that during the first phase, mostly decomposition of solid material occurs [5], and during the second phase, mostly decomposition of volatile intermediate products occurs. Sample decomposition effect may be overlaid with CL-20 sublimation process, which is described in the literature [13]. This process might take place in hermetical pans, but its participation in total endothermic effect will be very small because of high pressure in pan during the measurement. Two-stage decomposition in hermetical pan is connected with CL-20 and its intermediate degradation products decomposition. The lack of the second, clearly marked decomposition stage during the measurement performed with heating rate $2.0 \mathrm{~K} \mathrm{~min}^{-1}$ in the pan with hole indicates that volatile decomposition products abandoned the pan and the sublimation process participation is small.

The apparent activation energy and the pre-exponential factor with regard to the degree of conversion of the CL-20 decomposition for the measurements performed in hermetic pans are shown in Fig. 7.

In some papers, single values of the activation energy of the decomposition reaction of CL-20 are given [3, 4]. Due to the possible occurrence of many parallel and successive reactions during decomposition, as mentioned in the introduction, it is necessary to analyse the dependence of changes in the activation energy with regard to the degree of conversion [9]. According to Fig. 7, major changes in the apparent activation energy were shown, which are associated with the two-phase nature of the CL-20 decomposition process. For the degree of conversion, 0.02-0.15, the mean apparent activation energy of ${ }_{\mathrm{a}} \mathrm{Ea}=168 \pm 7 \mathrm{~kJ} \mathrm{~mol}^{-1}$ was determined, it is a value close to the literature data pointing to 161 [3] and $166 \mathrm{~kJ} \mathrm{~mol}^{-1}$ [5]. For the degree of conversion of $0.15 \leq \alpha \leq 0.50$, the apparent activation energy increases from $165 \pm 7$ to $296 \pm 32 \mathrm{~kJ} \mathrm{~mol}^{-1}$. It is due to the overlap of the first and second phase of the decomposition reaction. For the degree of conversion of $0.50 \leq \alpha \leq 0.80$, the apparent activation energy has a constant value typical for the second phase of decomposition. Within this range, the degree of conversion of the mean value of the apparent activation energy is ${ }_{\mathrm{a}} \mathrm{Ea}=295 \pm 36 \mathrm{~kJ} \mathrm{~mol}^{-1}$. Similar changes and the value of the activation energy were described in the literature [14]. The apparent activation energy ${ }_{\mathrm{a}} \mathrm{Ea}$ of the decomposition reaction of CL-20, polyNIMMO, PBAN and mixtures of polyNIMMO/CL-20, PBAN/CL-20, HTPB/CL-20 and GAP/CL-20 was determined. The apparent activation energy of the decomposition of HTPB was not determined due to the lack of visible exothermic decomposition of the sample during the performed measurement tests. The results are shown in Table 2.

The apparent activation energies of CL-20 and its mixtures with binders, determined for the initial decomposition stage $(0.05 \leq \alpha \leq 0.15)$, are compatible with each other within the limits of measurement error. The results do not indicate a destabilizing effect of polyNIMMO, PBAN, HTPB or GAP on the initial stage of the CL-20 decomposition. Significant reduction of the apparent activation energy by the binder in the second phase of the CL-20 decomposition is visible. This effect was observed in the analysis of compatibility based on the minimum decomposition peak. Reduction of the apparent activation energy of the second decomposition stage of CL-20 shows the influence of the intermediate reaction products on binders. This influence may be due to dissolution of volatile intermediate products of decomposition CL-20 in the binders or 
Fig. 7 Changes in the value of the apparent activation energy and the pre-exponential factor of the CL-20 decomposition with regard to the degree of conversion

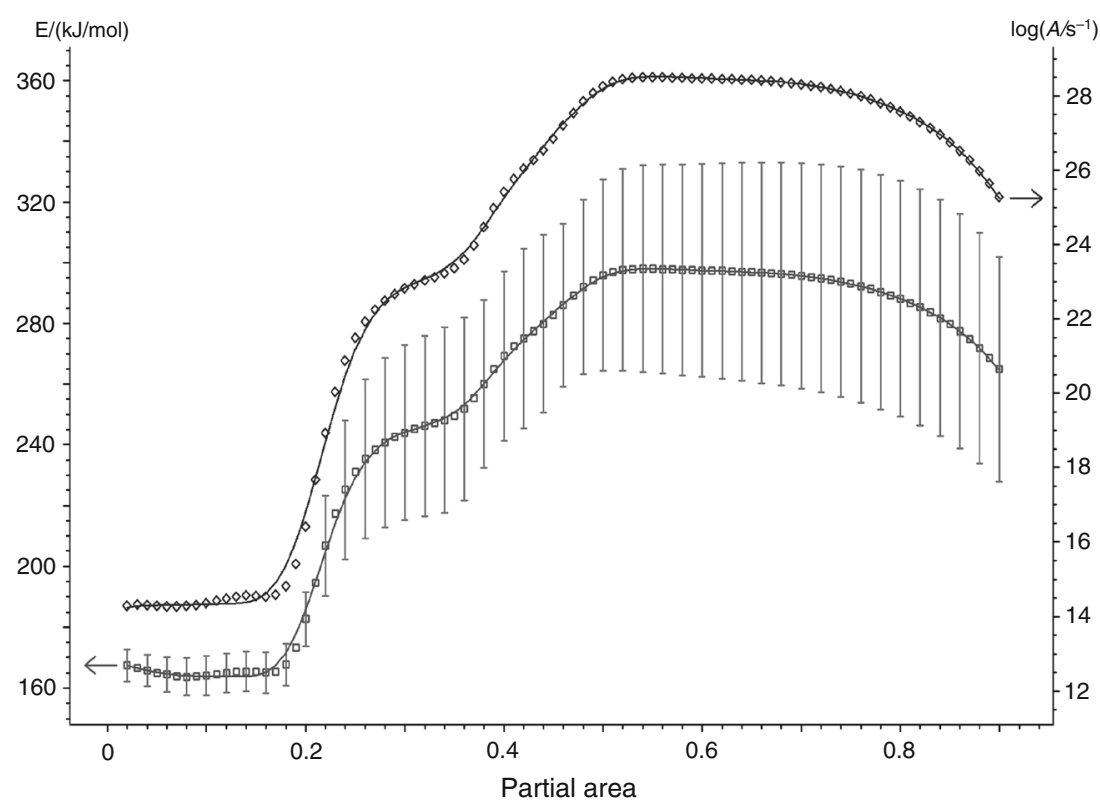

Table 2 Apparent activation energy ${ }_{\mathrm{a}} \mathrm{Ea}$ of the decomposition reaction of CL-20, polyNIMMO, PBAN and mixtures of polyNIMMO/CL-20, PBAN/CL-20, HTPB/CL-20 and GAP/CL-20

\begin{tabular}{|c|c|c|c|c|c|c|c|c|}
\hline$\alpha$ Reacted & CL-20 & PolyNIMMO & PolyNIMMO/CL-20 & PBAN & PBAN/CL-20 & HTPB/CL-20 & GAP & GAP/CL-20 \\
\hline \multicolumn{9}{|c|}{ The apparent activation energy ${ }_{\mathrm{a}} \mathrm{Ea} / \mathrm{kJ} \mathrm{mol}^{-1}$} \\
\hline 0.02 & $167 \pm 6$ & $164 \pm 3$ & $159 \pm 6$ & $76 \pm 25$ & $175 \pm 12$ & $169 \pm 8$ & $175 \pm 17$ & $134 \pm 7$ \\
\hline 0.05 & $165 \pm 6$ & $168 \pm 3$ & $164 \pm 3$ & $76 \pm 18$ & $174 \pm 13$ & $163 \pm 5$ & $160 \pm 6$ & $146 \pm 8$ \\
\hline 0.10 & $164 \pm 7$ & $169 \pm 3$ & $166 \pm 3$ & $78 \pm 14$ & $170 \pm 13$ & $159 \pm 3$ & $153 \pm 2$ & $157 \pm 9$ \\
\hline 0.15 & $165 \pm 7$ & $168 \pm 3$ & $168 \pm 3$ & $88 \pm 9$ & $168 \pm 13$ & $158 \pm 3$ & $152 \pm 2$ & $156 \pm 8$ \\
\hline 0.20 & $183 \pm 9$ & $167 \pm 3$ & $170 \pm 4$ & $91 \pm 9$ & $167 \pm 11$ & $158 \pm 3$ & $152 \pm 2$ & $153 \pm 7$ \\
\hline 0.25 & $231 \pm 25$ & $166 \pm 4$ & $173 \pm 6$ & $90 \pm 9$ & $166 \pm 10$ & $159 \pm 3$ & $152 \pm 2$ & $153 \pm 8$ \\
\hline 0.30 & $244 \pm 29$ & $165 \pm 4$ & $175 \pm 7$ & $87 \pm 9$ & $164 \pm 9$ & $160 \pm 4$ & $153 \pm 2$ & $154 \pm 8$ \\
\hline 0.35 & $249 \pm 31$ & $164 \pm 4$ & $176 \pm 9$ & $95 \pm 8$ & $162 \pm 9$ & $161 \pm 8$ & $153 \pm 2$ & $156 \pm 8$ \\
\hline 0.40 & $269 \pm 28$ & $163 \pm 4$ & $176 \pm 10$ & $99 \pm 7$ & $160 \pm 9$ & $164 \pm 12$ & $153 \pm 2$ & $156 \pm 7$ \\
\hline 0.45 & $283 \pm 28$ & $162 \pm 5$ & $174 \pm 11$ & $93 \pm 8$ & $158 \pm 10$ & $168 \pm 16$ & $153 \pm 2$ & $153 \pm 6$ \\
\hline 0.50 & $296 \pm 32$ & $161 \pm 5$ & $171 \pm 13$ & $90 \pm 9$ & $156 \pm 12$ & $174 \pm 21$ & $152 \pm 2$ & $146 \pm 6$ \\
\hline 0.55 & $298 \pm 35$ & $160 \pm 6$ & $166 \pm 14$ & $89 \pm 9$ & $155 \pm 14$ & $181 \pm 25$ & $152 \pm 2$ & $134 \pm 5$ \\
\hline 0.60 & $297 \pm 35$ & $159 \pm 7$ & $162 \pm 15$ & $88 \pm 10$ & $155 \pm 16$ & $189 \pm 31$ & $151 \pm 2$ & $104 \pm 6$ \\
\hline 0.65 & $297 \pm 37$ & $158 \pm 8$ & $159 \pm 16$ & $88 \pm 8$ & $157 \pm 18$ & $191 \pm 38$ & $151 \pm 2$ & $47 \pm 10$ \\
\hline 0.70 & $296 \pm 38$ & $156 \pm 10$ & $157 \pm 18$ & $86 \pm 6$ & $160 \pm 21$ & $158 \pm 39$ & $150 \pm 2$ & $62 \pm 17$ \\
\hline 0.75 & $293 \pm 39$ & $151 \pm 12$ & $155 \pm 21$ & $83 \pm 3$ & $168 \pm 26$ & $126 \pm 25$ & $148 \pm 2$ & $92 \pm 26$ \\
\hline 0.80 & $288 \pm 39$ & $141 \pm 17$ & $152 \pm 27$ & $79 \pm 4$ & $183 \pm 37$ & $144 \pm 14$ & $147 \pm 2$ & $132 \pm 8$ \\
\hline 0.85 & $280 \pm 39$ & $106 \pm 32$ & $150 \pm 38$ & $75 \pm 8$ & $190 \pm 66$ & $178 \pm 13$ & $145 \pm 1$ & $151 \pm 2$ \\
\hline 0.90 & $265 \pm 37$ & $29 \pm 36$ & $118 \pm 59$ & $71 \pm 11$ & $120 \pm 70$ & $189 \pm 19$ & $143 \pm 1$ & $147 \pm 2$ \\
\hline \multicolumn{9}{|c|}{ The average apparent activation energy ${ }_{\mathrm{a}} \mathrm{Ea} / \mathrm{kJ} \mathrm{mol}^{-1}$} \\
\hline $0.02-0.15$ & $165 \pm 7$ & $167 \pm 3$ & $164 \pm 4$ & $80 \pm 17$ & $172 \pm 13$ & $162 \pm 5$ & $160 \pm 7$ & $148 \pm 8$ \\
\hline $0.50-0.80$ & $295 \pm 36$ & $155 \pm 9$ & $160 \pm 18$ & $86 \pm 7$ & $162 \pm 21$ & $166 \pm 28$ & $150 \pm 2$ & $102 \pm 11$ \\
\hline
\end{tabular}

a physical separation of the CL-20 phase from the gas phase, ultimately leading to an increase in concentration of autocatalytic degradation products [15]. The analysis of activation energy changes at the initial stage of the decomposition does not confirm the influence of binders on polymorphic and thermal stability of CL-20 in polymers, 
described in the literature [2, 3, 6, 16-18]. It is connected with other conditions of performed experiments as well as with the fact that in the part of papers the minimum of decomposition peak was the analysed parameter. Also the content of impurities in the sample influences the polymorphic and thermal stability of CL-20 [13, 19].

The obtained results confirm that the determination of the compatibility based on the decomposition peak minimum has a number of drawbacks. First of all, the analysis of the decomposition peak minimum, which is observed for a large degree of conversion, for first-order $\alpha=0.61$ [20]. Analysis of the system properties with large degree of conversion refers to a mixture of the parent compound and degradation products (in the case of one-phase reaction) or a mixture containing only traces of the parent compound (in the case of multi-stage reaction, for example, trinitrotoluene decomposition, where $94 \%$ of the material reacts until $64 \%$ of thermal effect gets released [20]). For security reasons, we are interested in the properties of the parent compound. In addition, measurements made in pans with a pinhole are subjected to error due to the evaporation of the test substance or intermediate products of decomposition. The study of the thermal compatibility stability should be based on samples of high mass and performed in the lowest temperature [21, 22].

\section{Conclusions}

Compatibility of CL-20 with polyNIMMO, PBAN, HTPB and GAP was estimated according to STANAG 4147 standard and its modification consisting in the change of heating rate from $\beta=2$ to $\beta=10 \mathrm{~K} \mathrm{~min}^{-1}$. As it arises from STANAG 4147 standard criterion, CL-20 is not compatible with polyNIMMO, PBAN and GAP and possibly incompatible with HTPB. Changes of relative position of peaks between measurements performed in hermetical pans and pans with a pinhole and with different heating rate were observed. In case of polyNIMMO and HTPB, changes of measurement parameters lead to compatibility change.

Thermal decomposition of CL-20 is a two-phase process. The first phase is visible for the degree of conversion of $0.02 \leq \alpha \leq 0.15$ with the mean apparent activation energy of ${ }_{\mathrm{a}} \mathrm{Ea}=168 \pm 7 \mathrm{~kJ} \mathrm{~mol}^{-1}$. For the degree of conversion of $0.15 \leq \alpha \leq 0.50$, we observe the overlap of the first and second phase of the decomposition reaction and the increase of the apparent activation energy from $165 \pm 7$ to $296 \pm 32 \mathrm{~kJ} \mathrm{~mol}^{-1}$. For the degree of conversion of $\alpha=0.8$, the apparent activation energy has a constant value of ${ }_{\mathrm{a}} \mathrm{Ea}=295 \pm 36 \mathrm{~kJ} \mathrm{~mol}^{-1}$ typical for the second phase of decomposition. The results obtained indicate during the first phase, mostly decomposition of solid material occurs, and during the second phase, mostly decomposition of volatile intermediate products occurs. The apparent activation energies of the initial stage of decomposition $(0.05 \leq \alpha \leq 0.15)$ of CL-20 and its mixtures with binders are compatible with each other within the limits of measurement error. The results obtained do not indicate that polyNIMMO, PBAN, HTPB and GAP destabilize the initial stage of the CL-20 decomposition. The tested binders significantly reduce the apparent activation energy of the second stage of the CL-20 decomposition, which demonstrates their influence on indirect products of the CL-20 decomposition. Uncontrolled decomposition of a high-energy mixture, caused by the lack of compatibility, may lead to thermal explosion even at low degrees of conversion. For this reason, the compatibility test should be based on the analysis of the initial stage of decomposition.

Open Access This article is distributed under the terms of the Creative Commons Attribution License which permits any use, distribution, and reproduction in any medium, provided the original author(s) and the source are credited.

\section{References}

1. Książczak A, Maksimowski P, Gołofit T. Małosmugowe i ekologiczne paliwa rakietowe. Issues Armament Technol. 2005;95(2):133-41.

2. Liao LQ, Wei HJ, Li JZ, Fan XZ, Zheng Y, Ji YP, Fu XL, Zhang YJ, Liu FL. Compatibility of PNIMMO with some energetic materials. J Therm Anal Calorim. 2012;109:1571-6.

3. Lee JS, Jaw KS. Thermal decomposition properties and compatibility of CL-20, NTO with silicone rubber. J Therm Anal Calorim. 2006;85(2):463-7.

4. Zhang P, Guo XY, Zhang JY, Jiao QJ. Application of liquid paraffin in castable CL-20-based PBX. J Energ Mater. 2014;32(4): 278-92.

5. Yan QL, Zeman S, Elbeih A, Song ZW, Málek J. The effect of crystal structure on the thermal reactivity of CL-20 and its C4 bonded explosives (I): thermodynamic properties and decomposition kinetics. J Therm Anal Calorim. 2013;112(2):823-36.

6. Yan QL, Zeman S, Zhang TL, Elbeih A. Non-isothermal decomposition behavior of Fluorel bonded explosives containing attractive cyclic nitramines. Thermochim Acta. 2013;574:10-8.

7. NATO Standardisation Agreement (STANAG) 4147, Chemical compatibility of ammunition components with explosives (non nuclear applications); AC/310 (SG1) D/15 (Draft edition 2) I-96 NAVY/ARMY/AIR.

8. Jizhen L, Xuezhong F, Xiping F, Fengqi Z, Rongzu H. Compatibility study of 1,3,3-trinitroazetidinewith some energetic components and inert materials. J Therm Anal Calorim. 2006;85(3):779-84.

9. Vyazovkin S, Burnham AK, Criado JM, Burnham AK, Criado JM, Pérez-Maqueda LA, Popescu C, Sbirrazzuoli N. ICTAC kinetics committee recommendations for performing kinetic computations on thermal analysis data. Thermochim Acta. 2011;520:1-19.

10. Semenov NN. Chemical kinetics and chain reactions. London: Oxford University Press; 1935.

11. Abramov VG, Vaganova NI. Effect of a side reaction with small heat liberation on the critical thermal-explosion condition of the main selfcatalyzed reaction. Fiz Goreniya Vzryva. 1978;14(5): $135-41$. 
12. Friedman HL. Kinetics of thermal degradation of char-forming plastics from thermogravimetry. Application to phenolic plastic. J Polym Sci Part C. 1964;6(1):183-95.

13. Korsounskii BL, Nedel'ko VV, Chukanov NV, Larikova TS, Volk F. Kinetics of thermal decomposition of hexanitrohexaazaisowurtzitane. Russ Chem B. 2000;49(5):812-8.

14. Turcotte R, Vachon M, Kwok QSM, Wang R, Jones DEG. Thermal study of HNIW (CL-20). Thermochim Acta. 2005;433:105-15.

15. Książczak A, Książczak T. Influence of DSC measurement conditions on kinetic parameters of thermal decomposition of 2,4,6trinitrotoluene. J Therm Anal Calorim. 2000;60(1):25-33.

16. Torry S, Cunliffe A. Polymorphism and solubility of CL-20 in plasticisers and polymers. In: Proceedings of the 31st international annual conference of ICT, vol. 107, Karlsruhe, Germany, 27-30 June; 2000. p. 1-12.

17. Zhang $\mathrm{P}, \mathrm{Xu}$ J, Guo X, Jiao Q, Zhang J. Effect of addictives on polymorphic transition of $\varepsilon$-CL-20 in castable systems. J Therm Anal Calorim. 2014;117(2):1001-8.
18. Xiang M, Jiao Q, Zhu Y, Yu J, Chen L. Thermal study of HNIW(CL-20) and mixtures containing aluminum powder. J Therm Anal Calorim. 2014;116(3):1159-63.

19. Maksimowski P, Skupiński W, Szczygielska J. Comparison of the crystals obtained by precipitation of CL-20 with different chemical purity. Propellants Explos Pyrotech. 2013;38(6):791-7.

20. Janney IL, Rogers RN. Experimental thermochemical observations of condensed-phase reactions. In: Proceedings of the 11th North American thermal analysis society conference, vol. II; 1982. p. 643-9.

21. Książczak A, Maranda A, Rosenkiewicz D. Thermal Analysis of binary systems. Explosive-lead compound. J Therm Anal Calorim. 2000;60(1):97-102.

22. Cieślak K, Ksiażczak A, Zygmunt A. Determination of diphenylamine on initial thermal decomposition of single based propellant by using HFC. In: New trends in research of energetic materials, proceedings of the seminar, 16th, Pardubice, Czech Republic, vol. 1; 2013. p. 110-121. 